\title{
Surgical management of aortopulmonary window associated with interrupted aortic arch: A Congenital Heart Surgeons Society study
}

Igor E. Konstantinov, MD, PhD, ${ }^{a}$ Tara Karamlou, MD, ${ }^{a}$ William G. Williams, MD, ${ }^{a}$ Jan M. Quaegebeur, MD, Pedro J. del Nido, MD, ${ }^{c}$ Thomas L. Spray, MD, ${ }^{d}$ Christopher A. Caldarone, MD, ${ }^{\text {b }}$ Eugene H. Blackstone, MD, Brian W. McCrindle, MD, MPH, ${ }^{a}$ for the members of the Congenital Heart Surgeons Society

$\checkmark$ Supplemental material is available online.
From the a Hospital for Sick Children, Toronto, Canada; ' ${ }^{\mathrm{b}}$ Children's Hospital of New York, New York; 'Children's Hospital of Boston, Boston, Mass; ${ }^{\mathrm{d}}$ Children's Hospital of Philadelphia, Philadelphia, Pa; ${ }^{\mathrm{e}} \mathrm{Cleve-}$ land Clinic, Cleveland, Ohio.

Received for publication Jan 8, 2005; revisions received Feb 28, 2005; accepted for publication March 23, 2005.

Address for reprints: Brian W. McCrindle, MD, The Hospital for Sick Children 555 University Avenue, Toronto, Ontario, Canada M5G 1X8 (E-mail: brian.mccrindle@sickkids.ca).

J Thorac Cardiovasc Surg 2006;131:1136-41 $0022-5223 / \$ 32.00$

Copyright $\odot 2006$ by The American Association for Thoracic Surgery

doi:10.1016/j.jtcvs.2005.03.051
Objective: The objective was to determine outcomes and risk factors of surgical management of patients with aortopulmonary window associated with interrupted aortic arch.

Methods: From 1987 to 1997, 472 neonates with interrupted aortic arch were enrolled prospectively from 33 institutions. Associated aortopulmonary window was present in 20 patients. Competing risk methodology determined the prevalence of reintervention for postrepair pulmonary artery and aortic arch obstruction.

Results: Interrupted aortic arch was type A in 17 patients and type B in 3 patients. Aortopulmonary window morphology was type I $(n=10)$, type II $(n=5)$, and type III $(\mathrm{n}=5)$. Associated cardiovascular anomalies were common, including atrial septal defect $(\mathrm{n}=13)$ and systemic venous anomalies $(\mathrm{n}=3)$. Overall survival after initial admission was $91 \%, 86 \%$, and $84 \%$ at 1, 5, and 10 years, respectively. Fifteen patients underwent single-stage repair, and 4 patients underwent staged repair. There was an increased prevalence of patch augmentation of the interrupted aortic arch anastomosis in lower-weight infants $(2.3 \mathrm{~kg}$ vs $3.1 \mathrm{~kg}, P=.07)$. Competing risk analysis estimated that 5 years after repair, $51 \%$ had initial arch reintervention, $6 \%$ had initial pulmonary artery reintervention, and $43 \%$ were alive without reintervention. Reintervention for arch obstruction was more likely for those with interrupted aortic arch type B $(P=.08)$ and for those with higher weight at initial repair $(P=.003)$.

Conclusions: Complete correction of aortopulmonary window in the setting of interrupted aortic arch can be performed with low mortality in the neonatal period. Reinterventions for aortic arch obstruction are the most frequent complication after repair, but pulmonary artery stenosis also occurs. Use of patch augmentation may reduce the need for subsequent arch reintervention.

A ortopulmonary window (APW) is a communication between the ascending aorta and the pulmonary trunk, occurring above 2 normally formed semilunar valves. ${ }^{1,2}$ Isolated APW occurs in $0.2 \%$ of cases of congenital heart disease $^{3,4}$ and is accompanied by other cardiac anomalies in $52 \%$ of cases. ${ }^{5}$ Interrupted aortic arch (IAA) is the most frequently associated major lesion. The combination of APW and IAA is rare, and the cumulative experience with this combination of lesions is limited to isolated case reports. ${ }^{3,4,6-10}$ The presence of IAA with APW is a risk factor for death among those with APW. ${ }^{2}$ The surgical management of APW and IAA is necessarily complex, yet its rarity has precluded multivariable analysis from which therapeutic inferences could be derived. We sought to identify morphologic and procedural variables that are associated with 


\section{Abbreviations and Acronyms \\ APW $=$ aortopulmonary window \\ IAA $=$ interrupted aortic arch}

mortality or reintervention for either aortic arch or pulmonary artery obstruction after definitive repair.

\section{Patients and Methods}

Between 1987 and 1997, 472 neonates with IAA were prospectively enrolled from 33 Congenital Heart Surgeons Society member institutions. Twenty neonates $(4.2 \%)$ had associated APW. The number of patients enrolled with APW per institution ranged from 1 to 3 , with 2 institutions enrolling 3 patients. All patients with IAA admitted to a Congenital Heart Surgeons Society institution within 30 days of birth were eligible for inclusion. Participation by member institution was voluntary and confidential, and ethical approval was obtained per local requirements. Ethics approval for the Congenital Heart Surgeons Society Data Center is obtained annually from the Research Ethics Board of the Hospital for Sick Children, Toronto.

The Richardson classification was used in this report to classify APW types. ${ }^{11}$ IAA was defined as either a complete discontinuity or a nonpatent fibrous strand in the transverse arch or aortic isthmus. The types of IAA were described using Celoria and Patten's classification ${ }^{12}$ (Figure 1). Patients with right aortic arch and other associated aortic arch anomalies were identified and described individually.

Type I APW defects are located just above the sinus of Valsalva, on the posteromedial wall of the ascending aorta. ${ }^{11}$ Type II defects are more cephalad on the ascending aorta and involve the origin of the right pulmonary artery and the main pulmonary artery. Type III defects arise more laterally on the aorta, so that the right pulmonary artery takes anomalous origin from the posterior ascending aorta and is completely separated from the main pulmonary artery.

\section{Data Collection}

Data were abstracted from submitted copies of medical records requested for initial and subsequent assessments, admissions, and procedures. The most recent cross-sectional follow-up was performed between March and June 2004, with 3 deaths and follow-up completed for 11 (65\%) of 17 presumed survivors.

\section{Data Analysis}

The goals of the analysis were to describe morphologic and procedural characteristics, and to determine incremental risk factors for time-related mortality and reintervention directed at relieving either arch obstruction or pulmonary arterial obstruction after definitive repair. Data are given as frequency, median with range, or mean \pm standard deviation as appropriate, with the number of nonmissing values indicated. All data analyses were performed using SAS

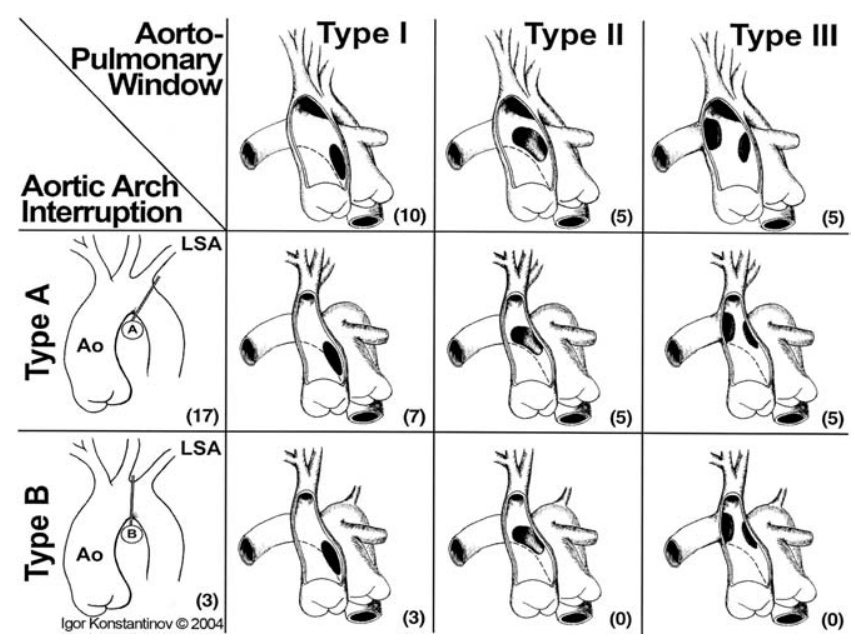

Figure 1. Morphologic subtypes of APW in IAA. Number of patients in each category (numbers in parentheses).

statistical software (version 9; SAS Institute, Inc, Cary, NC). Multiphase parametric modeling of the hazard function and competing risks methodology were used to define rates of transition to mutually exclusive time-related events and incremental risk factors associated with subsequent aortic arch reintervention as previously described. ${ }^{13,14}$ Variable selection was primarily performed by means of bootstrap bagging. ${ }^{14}$ For the bootstrap step, randomly selected data sets $(n=500)$ of the same size as the original data set were analyzed by means of automated stepwise regression, with an inclusion criterion of a $P$ value of .10 or less. For the aggregation step, cluster analysis was used to identify risk factors occurring in $50 \%$ of the analysis, with the most commonly occurring transformation (if applicable) selected. These factors were entered into a final model, and those with $P$ values of .10 or less were retained. Frequency of identifying factors (reliability) according to bagging is reported.

\section{Results}

\section{Patient Characteristics}

APW was found in 20 (4\%) of 472 enrolled neonates with IAA. Patient and morphologic characteristics are shown in Tables E1 and E2, Appendix.

\section{Associated Anomalies}

Associated cardiac anomalies were common, occurring in $15(75 \%)$ of the cohort. Atrial septal defect was the most common associated anomaly, with a prevalence of $65 \%$ (n $=13$ ). One patient had azygos continuation of the inferior vena cava, and 2 patients had a left superior vena cava draining to the coronary sinus. Anomalous origin of the right subclavian artery was present in 1 patient. Coronary artery anomalies were not found in our population. 
Noncardiac anomalies were present in 4 patients. One had CHARGE syndrome, consisting of cleft lip and palate, imperforate anus, and concomitant rectovaginal fistula. Hydrocephalus was present in 1 patient, and 1 infant had associated tracheoesophageal fistula with esophageal atresia. One neonate presented with deletion of the long arm of chromosome 21.

\section{Surgical Repair}

Aortic arch repair. Nineteen patients underwent repair of the IAA, and 1 patient died without intervention. Fifteen patients underwent single-stage repair of both the IAA and APW, and 4 patients underwent staged repair. The aortic arch was repaired directly without patch augmentation in 15 patients, with pericardial patch augmentation in 2 patients, and end-to-end repair using a left subclavian artery flap in 2 patients. Patch augmentation in 1 patient with Type II APW and Type A IAA was performed through a left aortotomy to close a defect in the back wall of the ascending aorta created after detachment of the pulmonary arteries. In the other patient with Type I APW and Type A IAA, the aortotomy extended from the superior aspect of the APW to the origin of the left subclavian artery. The pericardial patch was sewn to within 6 to $7 \mathrm{~mm}$ proximal to the end of this incision, and the descending aorta (after division of the left subclavian artery) was then anastomosed to the enlarged ascending aorta. The mean weight at repair was lower in those in whom patch augmentation was used $(2.3 \mathrm{~kg}$ vs $3.1 \mathrm{~kg}$, $P=.07)$.

$A P W$ repair. The repair technique for the APW varied according to surgeon preference and the underlying morphology (Table E2 Appendix). Twelve patients underwent closure through a transwindow approach (anterior approach of the APW with separation of both great arteries), and 7 patients underwent transaortic closure. Of those patients repaired using the transwindow approach, direct suture was used in 5, single patch technique was used in 5, and double patch closure was used in 2. A single patch without great vessel separation was used in the majority of neonates undergoing transaortic closure $(n=6)$, with 1 infant having single patch repair with complete separation of the aorta and pulmonary artery. One infant with anomalous origin of the right pulmonary artery from the ascending aorta (type III APW) underwent anterior translocation of the right pulmonary artery with anastomosis of the right pulmonary artery to the main pulmonary artery. A pericardial patch was used to augment this anastomosis, and the aortic defect was closed with a pericardial patch. Pericardial patches were most frequently used $(n=8)$, followed by a polytetrafluoroethylene (Gore-Tex; WL Gore Associates, Inc, Flagstaff, Ariz) patch $(\mathrm{n}=5)$ and Dacron patch $(\mathrm{n}=1)$ (Table E2 Appendix).

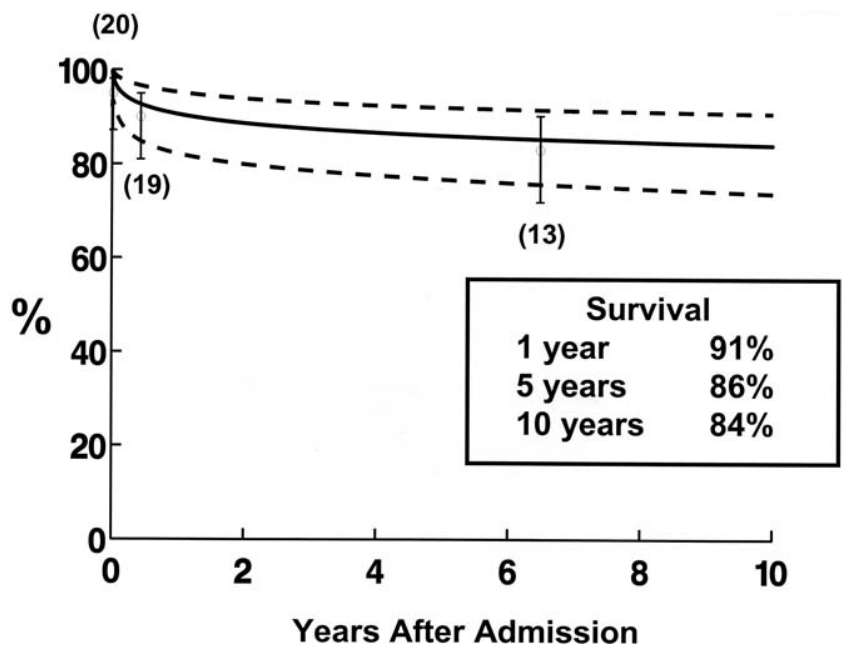

Figure 2. Time-related freedom from mortality in 20 neonates with APW and IAA was characterized by an early hazard phase. All patients began at the time of initial admission to a Congenital Heart Surgeons Society member institution. Parametric point estimates (solid lines); $70 \%$ confidence interval (dashed lines), nonparametric estimates (circles with error bars); number of patients at risk (numbers in parentheses).

Staged repair was performed in 4 patients, consisting of initial IAA repair followed by APW repair after 4, 8, 24, and 35 days. Two patients with known complex APW presented with profound acidosis and therefore underwent IAA repair followed by APW closure after resuscitation in the neonatal intensive care unit. However, in 2 other patients, the presence of an APW was not recognized on preoperative echocardiography. The postoperative convalescence in these 2 neonates was complicated by the development of congestive heart failure and ventilatory dependence. In both cases, subsequent cardiac catheterization revealed the presence of APW.

\section{Overall mortality}

There were 3 deaths (15\%) among the 20 patients. Two patients died after repair, and 1 patient with a complex chromosomal abnormality died without any intervention. Two deaths occurred early after IAA repair, including 1 patient who died within 2 months of IAA repair and 1 patient who died 5 months after repair. The death 5 months after repair followed balloon dilatation of residual aortic stenosis at the IAA repair site. Echocardiography 2 months before the patient's death demonstrated persistent aortic narrowing. The third death occurred 6 years after repair secondary to a seizure disorder. The time-related freedom from mortality after initial hospital admission is depicted in Figure 2. Survival from initial hospital admission was $91 \%$, $86 \%$, and $84 \%$ at 1,5 , and 10 years, respectively. Risk 
factors for overall mortality were not sought, owing to the small number of deaths.

\section{Reinterventions}

Aortic arch reinterventions. Reintervention for arch obstruction or bronchial compression occurred in 10 patients and included surgical relief of residual arch obstruction in 2, balloon dilatation of a discrete obstructing shelf in 6, aortic mobilization for bronchial compression in 1 , and placement of an aortic interposition graft for relief of bronchial compression in 1 (Table E3 Appendix). Additional percutaneous intervention for residual arch obstruction followed surgical relief of stenosis in 1 patient, and surgical repair of residual stenosis was required in 1 patient after balloon dilatation. One patient underwent 2 percutaneous interventions for relief of anastomotic narrowing at the IAA repair site.

Bronchial compression occurred 1 month after definitive repair in 2 patients, and involved the left mainstem bronchus in both cases. Neither patient had patch augmentation at the time of the IAA anastomosis. Undue tension at the end-toside aortic anastomosis was apparently responsible for the airway impingement. The diagnosis was made by bronchoscopy in 1 patient with prolonged ventilator dependence, and by magnetic resonance imaging in another in whom refractory left lower lobe collapse developed.

Pulmonary artery reintervention. The overall timerelated freedom from any pulmonary artery reintervention was $78 \%, 75 \%$, and $72 \%$ at 1,5 , and 10 years, respectively, after IAA repair (Figure E3 Appendix). Five patients underwent reintervention to relieve pulmonary artery stenosis. In 2 patients, pulmonary artery reintervention preceded aortic arch reintervention, and in 3 patients, pulmonary artery reintervention occurred concomitant with or after aortic arch reintervention. The pulmonary artery reinterventions that occurred before aortic arch reintervention consisted of balloon dilatation of the right pulmonary artery in 1 patient, and patch arterioplasty of right pulmonary artery stenosis in 1 patient (Table E3 Appendix). One patient underwent surgical repair of residual aortic stenosis and right pulmonary artery patch angioplasty. One patient underwent right pulmonary artery angioplasty and stent placement concomitant with balloon dilatation of residual aortic stenosis. The remaining patient underwent bilateral pulmonary artery patch angioplasties after aortic arch reintervention. Percutaneous right pulmonary arterioplasty was performed twice in 1 patient, and pacemaker implantation for iatrogenic heart block after surgical repair was required in 1 patient.

Five patients underwent 2 reinterventions, all after single-stage repair. One patient underwent 3 subsequent reinterventions after single-stage repair.

Competing risk methodology was used to determine the time-related freedom from initial aortic arch or pulmonary artery reintervention after IAA repair (Figure 3). These

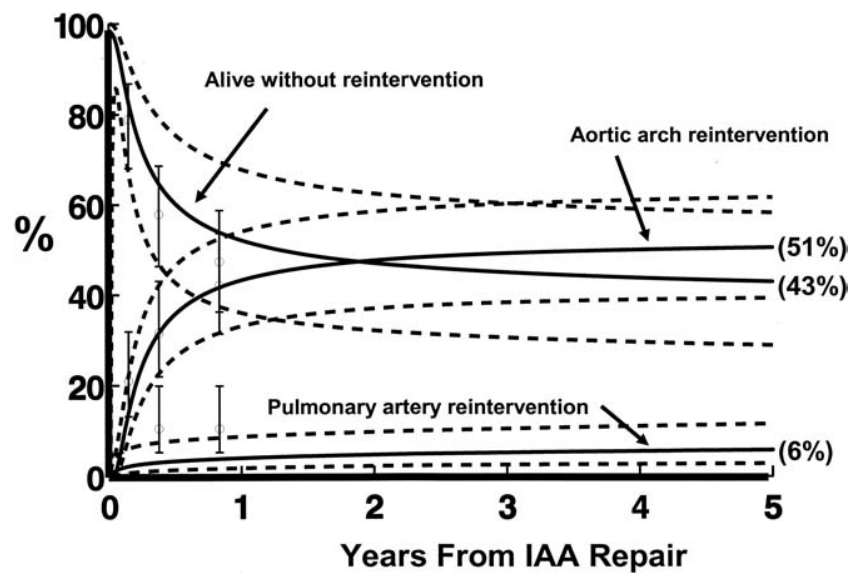

Figure 3. Competing risk analysis estimated that $\mathbf{5}$ years after definitive repair, $51 \%$ underwent initial arch reintervention, $6 \%$ underwent initial pulmonary artery reintervention, and $43 \%$ were alive without further intervention. No deaths occurred without subsequent reintervention.

events are mutually exclusive; therefore, patients are censored at the time of either arch reintervention or pulmonary artery reintervention, whichever occurred first. For example, the 3 patients who underwent pulmonary artery reintervention concomitant with or after aortic arch reintervention are modeled within the aortic arch reintervention stream rather than the pulmonary artery reintervention stream. There were no deaths before reintervention, and therefore death was not considered as a competing end-state within the context of this analysis. The competing risk analysis estimated that at 5 years after definitive repair, $51 \%$ had received initial arch reintervention, $6 \%$ had received initial pulmonary artery reintervention, and $43 \%$ were alive without reintervention.

The time-related freedom from aortic arch reintervention for arch obstruction or bronchial compression after initial IAA repair was characterized by a steep early hazard phase, which predominated for 1 year after initial repair and was responsible for 10 events (Figure 4). Freedom from aortic arch reintervention was $56 \%, 48 \%$, and $46 \%$ at 1,5 , and 10 years, respectively, post-IAA repair. Incremental risk factors from multivariable hazard modeling of arch reintervention without pulmonary artery intervention are higher birth weight (parameter estimate \pm standard error: $0.26 \pm 0.09$; bootstrap reliability $72 \% ; P=.004$ ) and the presence of Type B IAA (parameter estimate \pm standard error: $1.43 \pm$ 0.82 ; bootstrap reliability $50 \% ; P=.08$ ).

\section{Discussion}

In this study, morphologic and procedural characteristics, as well as outcomes, are described for the largest current cohort of neonates with APW in the setting of IAA. We also 


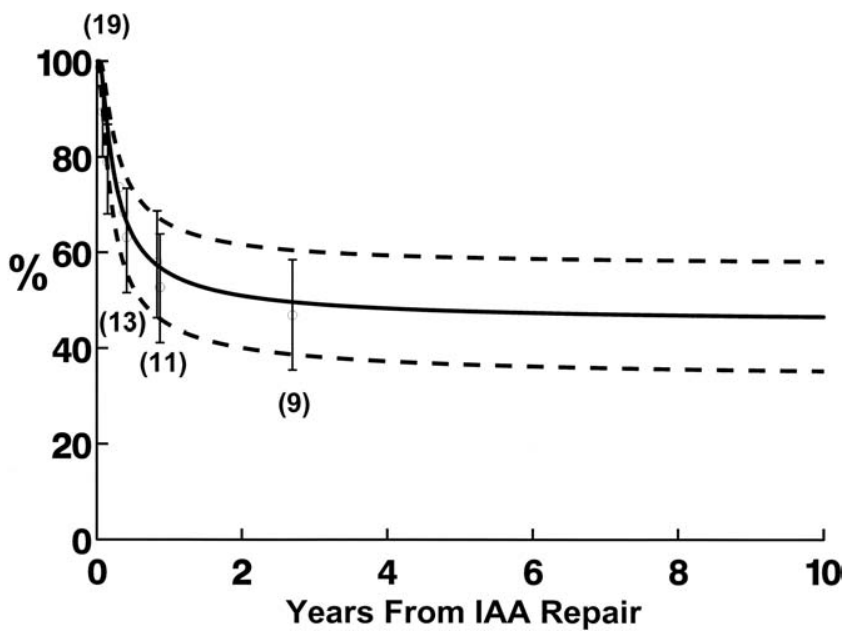

Figure 4. Time-related reintervention for arch obstruction in $\mathbf{1 9}$ neonates with APW and IAA was characterized by a steep early hazard phase. All patients began at the time of initial repair of IAA, and therefore 1 patient who died without intervention is not included in this analysis. Reintervention was required in $\mathbf{1 0}$ patients. Freedom from aortic reintervention was $56 \%$ at 1 year, $\mathbf{4 8} \%$ at 5 years, and $\mathbf{4 6} \%$ at 10 years. Parametric point estimates (solid lines); $70 \%$ confidence interval (dashed lines); nonparametric estimates (circles with error bars); number of patients at risk (numbers in parentheses).

defined associated risk factors associated with aortic arch reintervention after definitive repair.

The presence of associated cardiovascular lesions, particularly left-sided heart obstructive lesions, convey an increased risk of mortality in those with APW..$^{2-4,15}$ IAA is the most frequently encountered lesion associated with APW and is an independent risk factor for mortality. ${ }^{2}$ Outcomes in our cohort support this notion, because the clinical impact of concomitant IAA overshadowed that of the APW; that is, adverse outcomes, including reintervention and mortality, were directly related to the arch repair in most instances. Despite this unfavorable influence, 10-year survival in our cohort was similar to previously published reports of APW without concurrent complex anomalies, and significantly improved from those reported in preceding years. ${ }^{2-4,15,16}$ McElhinney and colleagues ${ }^{15}$ published their experience with 9 patients aged less than 6 months with APW in association with IAA who underwent operation between 1972 and 1995. Before 1984, the mortality rate was $33 \%$ in those with associated defects, whereas there were no reported deaths subsequent to this point. van Son and colleagues ${ }^{16}$ reported a similar finding in their historical review of 19 patients with APW not associated with IAA, in which APW division before 1962 was a risk factor for death. All 3 deaths in our series also occurred early in the experience, before 1992.
Surgical repair of APW and IAA includes closure of the APW (either through a transpulmonary, transwindow, or transaortic approach), reconstruction of the arch, and interruption of the ductus arteriosus..$^{1-3,7-10,13,17}$ Selection of the method of APW repair is influenced in part by the underlying morphology. At present, the transpulmonary approach has been supplanted by the transaortic approach as the preferred technique ${ }^{1-3,4,15}$ mainly because of a lower rate of reintervention for subsequent pulmonary artery stenosis. ${ }^{1-3,15}$ In addition, the transaortic approach allows superior visualization of the semilunar valves and coronary artery orifices, especially in type I APW where the left coronary orifice lies in immediate vicinity to the defect, and thus may be intimately involved in the repair. ${ }^{3,11,15}$ There is no uniform agreement regarding the superiority of either technique. ${ }^{18,19}$ In 1 series of 14 patients aged more than 1 year, ${ }^{18}$ adverse outcome was associated with transluminal repair. Others have likewise advocated a transwindow approach. ${ }^{19}$ Furthermore, implantation of a single patch through a transaortic approach theoretically may increase the potential for recurrence, because complete arterial separation is not achieved. ${ }^{1}$ Outcomes in our cohort were not associated with the method of APW closure, perhaps because the spectrum of options exercised was narrow. Indeed, the transpulmonary approach was never used.

Although mortality has improved in this population over time, the clinical course of patients after repair was dominated by a high rate of reintervention for both aortic arch and pulmonary artery obstruction. Previous reports have shown similar findings. ${ }^{1-4,15}$ We identified higher weight at initial repair and type B as incremental risk factors for arch reintervention. This unexpected finding might be because type III APW, which necessitates a more complex repair, was present in $80 \%(n=4)$ of patients with higher weight at initial repair. In addition, patients with higher mean repair weight, and presumptively larger aortic diameter, were less likely to have patch augmentation of their aortic anastomosis. We previously showed that avoidance of patch augmentation is associated with an increased risk of subsequent arch obstruction after IAA repair. ${ }^{20}$ Reticence to perform patch augmentation likely also contributes to the incidence of bronchial compression, a not infrequent complication in this lesion set that is related to increased anastomotic tension. ${ }^{1}$ Both patients in our series in whom airway compromise developed underwent direct aortic repair. Although type III APW, patch repair, and an interaction term between repair weight and patch augmentation were explored with multivariable analysis, the small number of events may have hampered our ability to demonstrate a statistical correlation between these variables and outcome.

Type B IAA was also associated with an increased prevalence of arch reintervention. Interruption of the arch proximal to the left subclavian artery increases the degree of 
aortic mobilization necessary to achieve a tension-free anastomosis. The higher rate of aortic arch obstruction in this morphologic subtype could therefore be related to inadequate mobilization of the descending aorta at the time of initial repair.

Single-stage reconstruction is currently the preferred approach, because early separation of the pulmonary and systemic circulations mitigates against the development of pulmonary hypertension, which can develop rapidly in the presence of uncorrected arterial level shunting. ${ }^{1-4,21}$ The importance of adequate echocardiographic assessment has been emphasized elsewhere, ${ }^{1,2,15,22}$ and is underscored in this report. A true degree of APW produces shunting that may be difficult to detect with Doppler, especially where flow may be further diminished by higher pulmonary resistance, or alternatively, by systemic hypotension in the setting of critical left-sided heart obstruction. APW was overlooked in 2 patients in our series who had inadvertent staged repair with the development of attendant postoperative complications secondary to inaccurate preoperative diagnosis.

\section{References}

1. Erez E, Dagan O, Georghiou GP, Gelber O, Vidne BA, Birk E. Surgical management of aortopulmonary window and associated lesions. Ann Thorac Surg. 2004;77:484-7.

2. Bagtharia RI, Trivedi KR, Burkhart HM, et al. Outcomes of patients with an aortopulmonary window and the impact of associated cardiovascular lesions. Cardiol Young. 2004;14:473-80.

3. Bagtharia R, Freedom RM, Yoo SJ. Aortopulmonary window. In: Freedom RM, Yoo SJ, Mikailian H, Williams WG, eds. The Natural and Modified History of Congenital Heart Disease. Blackwell, Mass; 2004:237-40

4. Hew CC, Bacha EA, Zurakowski D, del Nido PJ, Mayer JE, Jonas RA. Optimal surgical approach for repair of aortopulmonary window. Cardiol Young. 2001;11:385-90.

5. Kutsche LM, Van Meirop LHS. Anatomy and pathogenesis of aorticopulmonary septal defect. Am J Cardiol. 1987;59:443-7.

6. Carrel T, Pfammatter JP. Interrupted aortic arch, aorto-pulmonary window and aortic origin of the right pulmonary artery: single stage repair in the neonate. Eur J Cardiothrac Surg. 1997;12:668-80.

7. McMahon CJ, DiBardino DJ, Undar A, Fraser CD. Anomalous origin of left coronary artery from the right pulmonary artery in association with type III aortopulmonary window and interrupted aortic arch. Ann Thorac Surg. 2002;74:919-21.

8. Chiu IS, Wang JK, Wang MJ, Wang CC. One-stage repair of aortopulmonary septal defect and interrupted aortic arch. Ann Thorac Surg. 1994;58:1529-32.

9. Chiu IS, Wu SJ, Lee ML, et al. One stage repair of interrupted aortic arch and aortopulmonary window with an autologous arterial flap. J Card Surg. 1999;14:306-9.

10. Hata H, Shiono M, Sezai Y, Sumitomo N, Otsuka M, Harada K. One-stege repair of interrupted aortic arch and aortopulmonary window. Ann Thorac Surg. 1998;65:829-31.

11. Richardson JV, Doty DB, Rossi NP, Ehrenhaft JL. The spectrum of anomalies of aortopulmonary septation. J Thorac Cardiovasc Surg. 1979;78:21-7.

12. Celoria GC, Patton RB. Congenital absence of the aortic arch. Am Heart J. 1959;58:407-13.

13. Blackstone EH, Naftel DC, Turner ME. The decomposition of timevarying hazard into phases, each incorporating a separate stream of concomitant information. J Am Stat Assoc. 1986;81:615-24.

14. Blackstone EH, Rice TW. Clinical-pathological conference: use and choice of statistical methods for the clinical study, "Superficial adenocarcinoma of the esophagus." J Thorac Cardiovasc Surg. 2001;122: 1063-76.

15. McElhinney DB, Reddy VM, Tworetzky W, Silverman NH, Hanley FL. Early and late results after repair of aortopulmonary septal defect and associated anomalies in infants $<6$ months of age. Am J Cardiol. 1998;81:195-201.

16. van Son JAM, Puga FJ, Danielson GK, et al. Aortopulmonary window: factors associated with early and late success after surgical treatment. Mayo Clin Proc. 1993;68:128-33.

17. Doty DB, Richardson JV, Falkovsky GE, Gordonova MI, Burakovsky VI. Aortopulmonary septal defect: hemodynamics, angiography, and operation. Ann Thorac Surg. 1881;32:243-50.

18. Prasad TR, Valiathan MS, Shyamakrishnan KG, Venkitachalam CG. Surgical management of aortopulmonary septal defect. Ann Thorac Surg. 1989;47:877-9.

19. Tiraboschi R, Salmone G, Crupi G, et al. Aortopulmonary window in the first year of life: report on 11 cases. Ann Thorac Surg. 1988;46: $438-41$.

20. McCrindle BW, Tchervenkov CI, Konstantinov IE, Neirott RA, Jacobs ML, Blackstone EH. Risk factors associated with mortality and reinterventions in 474 neonates with interruption of the aortic arch: a congenital heart surgeons society study. J Thorac Cardiovasc Surg. 2005;129:343-50.

21. Bertolini A, Dalmonte P, Bava GL, et al. Aortopulmonary septal defects: a review of the literature and report of ten cases. J Cardiovasc Surg. 1994;35:207-13.

22. Di Bella I, Gladstone DJ. Surgical management of aortopulmonary window. Ann Thorac Surg. 1998;65:768-70. 
TABLE E1. Patient characteristics at the time of admission ( $n=20)$

\begin{tabular}{lc}
\hline \multicolumn{1}{c}{ Variable } & Value \\
\hline Demographic characteristics & \\
Weight at IAA repair (kg, median and range) & $2.9(2.1-4.3)$ \\
Age at IAA repair (days, median and range) & $7(3-39)$ \\
Gender (female/male) & $13(65 \%)$ \\
Noncardiac anomaly & $4(20 \%)$ \\
Associated cardiac anomalies & \\
ASD & $13(65 \%)$ \\
Left SVC & $2(10 \%)$ \\
Azygous continuation of IVC & $1(5 \%)$ \\
Anomalous RSCA & $1(5 \%)$ \\
\hline
\end{tabular}

$>I A A$, Interrupted aortic arch; $A S D$, atrial septal defect; $S V C$, superior vena cava; $I V C$, inferior vena cava; $R S C A$, right subclavian artery.
TABLE E2. Procedural characteristics at interrupted aortic arch and aortopulmonary window repair (n

= 19)

\begin{tabular}{|c|c|}
\hline Variable & Value \\
\hline \multicolumn{2}{|l|}{ Demographics } \\
\hline Single-stage repair & $15(79 \%)$ \\
\hline \multicolumn{2}{|l|}{ Technique of arch repair } \\
\hline Median sternotomy & $15(75 \%)$ \\
\hline Thoracotomy & $4(20 \%)$ \\
\hline \multicolumn{2}{|l|}{ Type of repair of IAA } \\
\hline Direct anastomosis without patch & $15(79 \%)$ \\
\hline Direct anastomosis with patching & $2(10 \%)$ \\
\hline Direct anastomosis with LSCA flap & $2(10 \%)$ \\
\hline \multicolumn{2}{|l|}{ Type of repair of APW } \\
\hline $\begin{array}{l}\text { No separation of great vessels with patch } \\
\text { closure from within aorta }\end{array}$ & $6(30 \%)$ \\
\hline $\begin{array}{l}\text { Separation of great vessels with suture } \\
\text { repair of aorta and PA }\end{array}$ & $5(26 \%)$ \\
\hline $\begin{array}{l}\text { Separation of great vessels with patch repair } \\
\text { of PA }\end{array}$ & $5(26 \%)$ \\
\hline $\begin{array}{l}\text { Separation of great vessels with patch repair } \\
\text { of aorta and PA }\end{array}$ & $2(11 \%)$ \\
\hline $\begin{array}{l}\text { Separation of the great vessels with patch } \\
\text { repair from within aorta }\end{array}$ & $1(5 \%)$ \\
\hline \multicolumn{2}{|l|}{ Patch material for aortic defect } \\
\hline $\begin{array}{l}\text { Polytetrafluoroethylene (Gore-Tex; WL } \\
\text { Gore Associates, Inc, Flagstaff, Ariz) }\end{array}$ & $5(26 \%)$ \\
\hline Dacron & $2(11 \%)$ \\
\hline Pericardial & $2(11 \%)$ \\
\hline \multicolumn{2}{|l|}{ Patch material for pulmonary artery defect } \\
\hline Pericardial & $8(42 \%)$ \\
\hline Polytetrafluoroethylene (Gore-Tex) & $5(26 \%)$ \\
\hline
\end{tabular}

$\overline{I A A}$, interrupted aortic arch; $A P W$, aortopulmonary window; $L S C A$, left subclavian artery; $P A$, pulmonary artery. 


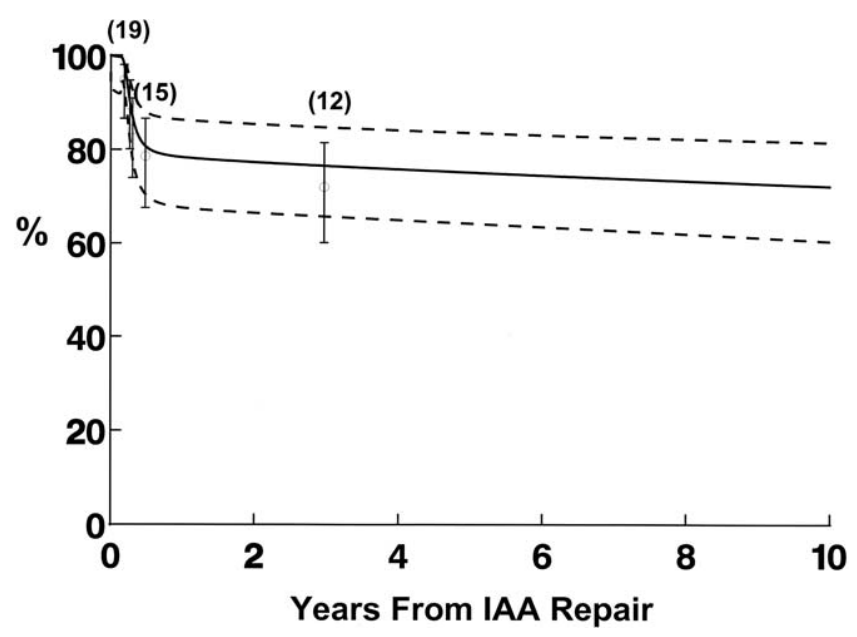

Figure E3 (Appendix). Overall time-related freedom from reintervention for pulmonary artery obstruction after repair of APW and IAA in 19 neonates. Five patients underwent reintervention after single-stage repair in infancy. In 3 patients, pulmonary artery reintervention occurred concomitant with or after aortic arch reintervention. Overall freedom from reintervention was $78 \%$ at 1 year, $75 \%$ at 5 years, and $72 \%$ at 10 years. Parametric point estimates (solid lines); 70\% confidence interval (dashed lines); nonparametric estimates (circles with error bars); number of patients at risk (numbers in parentheses).

TABLE E3. Reinterventions on the aortic arch or pulmonary arteries

\begin{tabular}{|c|c|c|}
\hline Patient & No. reinterventions & Description of procedures \\
\hline \multirow[t]{2}{*}{1} & 2 & Surgery for residual aortic narrowing \\
\hline & & Balloon dilatation of residual aortic narrowing \\
\hline \multirow[t]{2}{*}{2} & 2 & Mobilization of aorta for bronchial compression \\
\hline & & Interposition graft placement for bronchial compression \\
\hline 3 & 1 & Balloon dilatation of residual aortic narrowing \\
\hline 4 & 1 & RPA patch arteroplasty \\
\hline 5 & 1 & Surgery for residual aortic narrowing \\
\hline 6 & 1 & Balloon dilatation of residual aortic narrowing \\
\hline \multirow[t]{2}{*}{7} & 2 & Balloon dilatation of residual aortic narrowing \\
\hline & & Surgery for residual aortic narrowing + RPA patch arteroplasty \\
\hline \multirow[t]{2}{*}{8} & 2 & RPA balloon arteroplasty \\
\hline & & RPA balloon arteroplasty \\
\hline 9 & 1 & Balloon dilatation of residual aortic narrowing \\
\hline 10 & 1 & Surgery for residual aortic narrowing \\
\hline \multirow[t]{2}{*}{11} & 2 & Balloon dilatation of residual aortic narrowing + RPA Stent \\
\hline & & Balloon dilatation of residual aortic narrowing + LPA balloon arteroplasty \\
\hline \multirow[t]{3}{*}{12} & 3 & Balloon dilatation of residual aortic narrowing \\
\hline & & Surgery for residual aortic narrowing \\
\hline & & RPA + LPA patch arteroplasty + pacemaker implantation \\
\hline 13 & 1 & Interposition graft for bronchial compression \\
\hline
\end{tabular}

$R P A$, Right pulmonary artery; $L P A$, left pulmonary artery. 